\title{
Enhancement of asymmetric
} bioreduction of N,N-dimethyl-3keto-3-(2-thienyl)-1-propanamine to corresponding $(S)$-enantiomer by fusion of carbonyl reductase and glucose dehydrogenase

\author{
Taiqiang Sun ${ }^{1 \dagger}$, Bin $\mathrm{Li}^{1+}$, Yao Nie ${ }^{1 *}$, Dong Wang ${ }^{1 *}$ and Yan $\mathrm{Xu}^{1,2}$
}

\begin{abstract}
Background: (S)-(-)-N,N-Dimethyl-3-hydroxy-3-(2-thienyl)-1-propanamine (DHTP) is a key intermediate for the preparation of (S)-duloxetine, an important antidepressant drug. However, so far, the catalytic efficiency of (S)-DHTP synthesis by asymmetric bioreduction is yet limited. The present study aims to develop an efficient system for synthesis of (S)-DHTP by bioreduction.

Results: Various recombinant carbonyl reductases were evaluated for asymmetric reduction of N,N-dimethyl-3-keto3-(2-thienyl)-1-propanamine (DKTP) to produce (S)-DHTP. The NADPH-dependent carbonyl reductase CR2 was identified as the suitable candidate, giving (S)-DHTP in absolute configuration. Then the fusion protein involving CR2 and glucose dehydrogenase (CR2-L-GDH) was constructed to further improve cofactor regeneration and resulted catalytic efficiency of the enzymatic reduction. By studying the effects of reaction conditions involving cofactor regeneration, suitable catalytic system was achieved for CR2-L-GDH catalyzing (S)-DHTP synthesis. Consequently, (S)-DHTP (>99.9\% e.e.) with yield of $97.66 \%$ was obtained from $20 \mathrm{~g} \mathrm{~L}^{-1}$ DKTP within 8-h reaction, employing $40 \mathrm{~g} \mathrm{~L}^{-1}$ glucose and $0.1 \mathrm{mmol} \mathrm{L}^{-1} \mathrm{NADP}^{+}$to drive the cofactor regeneration, resulting in the space-time yield of $2.44 \mathrm{~g} \mathrm{~L}^{-1} \mathrm{~h}^{-1}$.

Conclusion: Optically pure (S)-DHTP with improved yield was obtained by fusion enzyme CR2-L-GDH. Fusion enzyme-mediated biocatalytic system would be promising to enhance reaction efficiency of enzyme-coupled system for preparation of optically active alcohols.
\end{abstract}

Keywords: Asymmetric reduction, Carbonyl reductase, Glucose dehydrogenase, Fusion enzyme, Cofactor regeneration

\section{Background}

Optically active alcohols are valuable and promising chiral building blocks imposed in the production of

\footnotetext{
*Correspondence: ynie@jiangnan.edu.cn; dwang@jiangnan.edu.cn

†Taiqiang Sun and Bin Li contributed equally to this work

${ }^{1}$ School of Biotechnology and Key Laboratory of Industrial

Biotechnology, Ministry of Education, Jiangnan University, 1800 Lihu

Road, Wuxi 214122, China

Full list of author information is available at the end of the article
}

pharmaceuticals, agrochemicals, functional materials, and fine chemicals (Munoz Solano et al. 2012; Ni and Xu 2012; Patel 2008). Optically active heterocyclic alcohols have been widely used as important precursors for the synthesis of chiral drugs (Huisman and Collier 2013; Pesti and DiCosimo 2003; Pollard and Woodley 2007). Using optically active heterocyclic alcohols as the key intermediate, $(S)$-duloxetine, the effective antidepressant and potent dual inhibitor of serotonin and norepinephrine 
reuptake (Bymaster et al. 2001), can be prepared in high optical purity.

The preparation of single enantiomers of chiral intermediates has become particularly prevalent in the pharmaceuticals industry (Patel 2003, 2008). Currently, enantiopure chiral alcohols can be acquired by ether chemical or biological strategies. Compared with chemical synthesis, biocatalytic route has become a subject of considerable interest due to its high chemo-, regio-, and enantioselectivities, and mild reaction conditions and environmental benignity (Lalonde 2016; $\mathrm{Ni}$ and $\mathrm{Xu} 2012$; Wohlgemuth 2010). In recent years, enzymatic asymmetric reduction of prochiral ketones for preparation of optically active alcohols has gained increasing favor (Nakamura et al. 2003; Nealon et al. 2015; Noey et al. 2015; Sun et al. 2016; Wang et al. 2011).

Based on the retrosynthetic strategy, biosynthesis of (S)-(-)-N,N-dimethyl-3-hydroxy-3-(2-thienyl)-1propanamine (DHTP) or its substituted derivatives has been identified as the straightforward and efficient way for the preparation of $(S)$-duloxetine (Fig. 1) (Ren et al. 2015; Tang et al. 2011; Wada et al. 2004; Zhang et al. 2015). Immobilized cells of Saccharomyces cerevisiae have been applied to produce $(S)-(-)-3-\mathrm{N}$-methylamino1-(2-thienyl)-1-propanol with the optical purity of 99\% enantiomeric excess (e.e.) and conversion of $100 \%$ under the substrate concentration of $5 \mathrm{~g} \mathrm{~L}^{-1}$ after reaction for $48 \mathrm{~h}$ (Ou et al. 2014). Otherwise, the whole-cell catalytic system using Candida tropicalis has been developed to produce $(S)$-DHTP with $99 \%$ e.e. at the conversion of $84 \%$, while the substrate tolerance of this system was merely $1 \mathrm{~g} \mathrm{~L}^{-1}$ (Soni and Banerjee 2005). Although optically pure $(S)$-DHTP can be prepared by biocatalytic reductions, the substrate concentration and the corresponding space-time yield of the whole-cell bioprocesses are yet limited. Therefore, it would be necessary to develop suitable carbonyl reductase and the corresponding enzymatic system for efficient synthesis of (S)-DHTP.
Carbonyl reductases require stoichiometric amounts of nicotinamide cofactors (NADH or NADPH) as hydrogen donator for their activities. In situ cofactor regeneration would be feasible and prerequisite for practical application of carbonyl reductase-catalyzed ketone reductions. Of the cofactor regeneration approaches, enzyme-coupled system has been developed and is particular preferred for enzymatic reactions. Glucose dehydrogenase (GDH) as the coupled enzyme has been widely applied in $\mathrm{NAD}(\mathrm{P}) \mathrm{H}$ regeneration (Gao et al. 2013; Ye et al. 2010), due to its advantageous features of accessibility and practicability (Hall and Bommarius 2011). For enzyme coupling, construction of fusion protein has been developed as an effective method for cofactor regeneration, where two coding genes are combined by a short linker sequence to yield a single polypeptide exhibiting at least two functions (Calam et al. 2016; Farrow et al. 2015; Suehrer et al. 2014). The proximity effect of fusion protein generally reduces the intermediate diffusion distance and therefore increases the probability of intermediate undergoing a sequential reaction step before escaping by diffusion (Conrado et al. 2008; Dueber et al. 2009). In addition, the active sites of different enzymes for consecutive reactions can be brought in close proximity to accelerate the processing of intermediate through channeling (Castellana et al. 2014). Fusion protein of oxidoreductases would greatly facilitate the involved cofactor transfer between the two active centers of both the enzyme for catalysis and the coupled enzyme for cofactor regeneration, resulting in accumulation of necessary cofactor close to active center in some level and enhancement of desired biocatalytic reaction (Pazmino et al. 2008; Prachayasittikul et al. 2006).

In this study, various recombinant carbonyl reductases were evaluated for asymmetric reduction of N,N-dimethyl-3-keto-3-(2-thienyl)-1-propanamine (DKTP) to produce $(S)$-DHTP. Then the NADPH-dependent carbonyl reductase CR2 was obtained as the suitable candidate

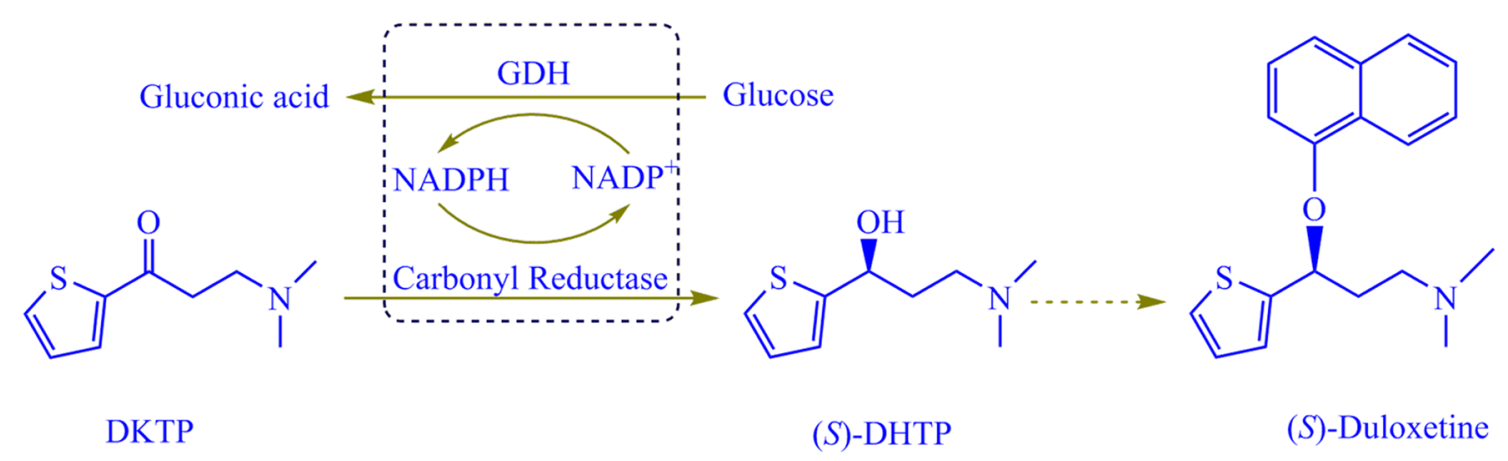

Fig. 1 Scheme for (S)-duloxetine synthesis from bioreduction of DKTP to (S)-DHTP involving fusion-based enzyme-coupled system 
catalyzing asymmetric reduction. To efficiently improve the preparation of $(S)$-DHTP, GDH was introduced to construct the fusion enzyme CR2-L-GDH. Finally, the fusion enzyme-involved reaction conditions were optimized, and compared with free enzymes involving CR2 and GDH, the fusion enzyme system was employed for the production of the key intermediate of $(S)$-duloxetine (Fig. 1).

\section{Methods \\ Materials}

DKTP, $(S)$-DHTP, and (R)-DHTP were purchased from TCI (Shanghai) Development Co., Ltd. The cofactors including $\mathrm{NAD}(\mathrm{P})^{+}$and $\mathrm{NAD}(\mathrm{P}) \mathrm{H}$ were obtained from Sigma-Aldrich (St. Louis, USA). Diethylamine, ethyl acetate, $\mathrm{n}$-hexane, and isopropanol used for high-performance liquid chromatography were of chromatographic grade from Sigma-Aldrich (St. Louis, USA). All other chemicals used in this study were of analytical grade and commercially available.

\section{Construction of fusion enzyme comprising CR2 and GDH} Fusion expression system containing CR2 (GenBank Accession Number: AB183149) and GDH (GenBank Accession Number: WP_013351020) was constructed using an aligned spacing sequence (GGGGSGGGGSG GGGS) as the peptide linker between them. The forward primer 5'-GGAATTCCATATGATGACATTTACAGTGG TGACAG GC- $3^{\prime}$ and the reverse primer $5^{\prime}$-AGAGCCAC CACCGCCAGAGCCACCACCGCCAG AGCCACCAC CGCCCCCACGGTACGCGCC-3' were used to amplify the fusion gene encoding CR2 and the linker. The forward primer 5'-GGCGGTGGTGGCTCTGGCGG TGGT GGCTCTGGCGGTGGTGGCTCTATGTATCCGGATT TAAAAGGAAAAG-3' and the reverse primer $5^{\prime}$-ATAAGA ATGCGGCCGCTTAACCGCGGCCTGC-3' ${ }^{\prime}$ were used to amplify the fusion gene encoding the linker and GDH. The fusion gene $\mathrm{cr} 2-l-g d h$ was cloned using the overlapextension technique on the vector of pET-28a at the NdeI and NotI restriction sites. The recombinant plasmid pET28a-cr2-l-gdh was transformed into the competent Escherichia coli BL21(DE3), and the positive E. coli BL21(DE3)/ pET-28a-cr2-l-gdh was verified by DNA sequencing. The recombinant plasmid provides the fusion protein CR2-LGDH with a six-His tag at the $\mathrm{N}$-terminus.

\section{Microorganisms and cultivation}

The recombinant strains expressing candidate enzymes for DKTP reduction and the recombinant $E$. coli BL21(DE3)/pET-28a-gdh expressing GDH used in this study were constructed and expressed previously in our laboratory (Table 1) (Li et al. 2016). For GDH and the fusion protein CR2-L-GDH, the medium for recombinant strains cultivation was Luria-Bertani (LB) broth containing $50 \mu \mathrm{g} \mathrm{mL}^{-1}$ kanamycin, and for CR2, the recombinant cells were cultured in LB broth containing $100 \mu \mathrm{g} \mathrm{mL}^{-1}$ ampicillin. Regarding all the recombinants used in this study, the cells were grown in $5 \mathrm{~mL} \mathrm{LB}$ broth comprising the corresponding antibiotic at $37^{\circ} \mathrm{C}$ and $200 \mathrm{rpm}$ for $8-10 \mathrm{~h}$. Then the culture was transferred into a $2000 \mathrm{~mL}$ Erlenmeyer flask containing $500 \mathrm{~mL}$ fresh LB medium with the corresponding antibiotic. When the $\mathrm{OD}_{600}$ value of the culture reached $0.6-0.8,1.0 \mathrm{mmol} \mathrm{L}^{-1}$ isopropyl $\beta$-D-thiogalactopyranoside (IPTG) was added to induce protein expression. The cultures were cultivated at $17^{\circ} \mathrm{C}$ for $14 \mathrm{~h}$, and then the cells were harvested by centrifugation and washed three times with physiological saline for further use.

\section{Preparation of crude enzyme}

The recombinant cells were suspended in Triethanolamine- $\mathrm{H}_{3} \mathrm{PO}_{4}$ (TEA buffer) $\left(0.1 \mathrm{~mol} \mathrm{~L}{ }^{-1}, \mathrm{pH} 8.0\right)$ and disrupted by sonication with an ultrasonic oscillator (Sonic Materials Co., USA). The cell debris was removed by centrifugation at $4{ }^{\circ} \mathrm{C}$ and $18,000 \times g$ for $30 \mathrm{~min}$, and the supernatant was used as the crude enzyme for catalyzing the asymmetric reduction of the substrate DKTP. The concentration of crude enzyme was expressed as $2 \mathrm{~g} \mathrm{~L}^{-1}$ total soluble protein for biocatalytic asymmetric reactions in this work.

\section{Purification of recombinant enzymes}

The harvested cells were suspended in TEA buffer (0.1 $\mathrm{mol} \mathrm{L}^{-1}, \mathrm{pH} \mathrm{8.0)}$ and treated with sonication using an ultrasonic oscillator (Sonic Materials Co., USA). The cell debris were removed by centrifugation $(18,000 \times g$, $30 \mathrm{~min})$ at $4{ }^{\circ} \mathrm{C}$, and the supernatant was applied to a HisTrap HP affinity column (GE Healthcare, USA) equilibrated with the buffer $\left(20 \mathrm{mmol} \mathrm{L}{ }^{-1}\right.$ Tris- $\mathrm{HCl}$, $0.3 \mathrm{~mol} \mathrm{~L}^{-1} \mathrm{NaCl}, 40 \mathrm{mmol} \mathrm{L}^{-1}$ imidazole, $\mathrm{pH}$ 8.0) on an ÄKTA purifier system (GE Healthcare, USA). Then the absorbed proteins were eluted with a 40-min linear imidazole gradient buffer $\left(0-0.5 \mathrm{~mol} \mathrm{~L}^{-1}\right.$ imidazole, $20 \mathrm{mmol} \mathrm{L}^{-1}$ Tris- $\mathrm{HCl}, 0.3 \mathrm{~mol} \mathrm{~L}^{-1} \mathrm{NaCl}, \mathrm{pH} 8.0$ ) at a flow rate of $3 \mathrm{~mL} \mathrm{~min}^{-1}$ and the purified fractions were exchanged into the buffer $\left(20 \mathrm{mmol} \mathrm{L}^{-1}\right.$ Tris- $\mathrm{HCl}$, $0.3 \mathrm{~mol} \mathrm{~L}^{-1} \mathrm{NaCl}, \mathrm{pH} 8.0$ ) using disposable PD-10 desalting columns (GE Healthcare, USA) (Li et al. 2016). The preparations of purified enzymes were applied to activity assay and measurement of kinetic parameters.

\section{Enzyme assay and kinetic parameters}

The enzyme assay mixture in $100 \mu \mathrm{L}$ for reducing DKTP or oxidating glucose activity of the purified CR2-L-GDH comprised $0.1 \mathrm{~mol} \mathrm{~L}^{-1}$ TEA buffer ( $\mathrm{pH} 8.0$ ), $5 \mathrm{mmol} \mathrm{L}^{-1}$ DKTP or $4 \mathrm{mmol} \mathrm{L}^{-1}$ glucose, $0.5 \mathrm{mmol} \mathrm{L}^{-1} \mathrm{NAD}(\mathrm{P})$ 
Table 1 Selection of the recombinant enzymes for catalyzing DKTP reduction to (S)-DHTP

\begin{tabular}{|c|c|c|c|c|}
\hline Enzyme & GenBank ID & Source & Product configuration/yield (\%) & References \\
\hline S1 & AB036927 & Candida magnoliae & - & Kizaki et al. (2001) \\
\hline C1 & AB084515 & C.parapsilosis & - & Kataoka et al. (2004) \\
\hline C2 & AB084516 & C. parapsilosis & - & Kataoka et al. (2004) \\
\hline ADHR & AY267012 & Lactobacillus kefiri & - & Weckbecker and Hummel (2006) \\
\hline CR2 & AB183149 & Kluyveromyces marxianus & $S / 91.31 \pm 0.45$ & Kataoka et al. (2006) \\
\hline CR4 & E59061 & K. aestuarii & - & Yamamoto et al. (2004) \\
\hline KRD & AF178079 & Zygosaccharomyces rouxii & $S / 55.18 \pm 0.25$ & Costello et al. (2000) \\
\hline OYE & AB126227 & K. marxianus & - & Kataoka et al. (2002) \\
\hline$R C R$ & DQ295067 & C. parapsilosis & - & Nie et al. (2008) \\
\hline SCR & DQ675534 & C. parapsilosis & - & Nie et al. (2011) \\
\hline SCR1 & FJ939565 & C. parapsilosis & - & Nie et al. (2011) \\
\hline SCR3 & FJ939564 & C. parapsilosis & - & Nie et al. (2011) \\
\hline CPAR1 & JX512911 & C. parapsilosis & - & Guo et al. (2014) \\
\hline CPAR2 & JX512912 & C. parapsilosis & - & Guo et al. (2014) \\
\hline CPAR3 & JX512913 & C. parapsilosis & - & Guo et al. (2014) \\
\hline CPAR4 & JX512915 & C. parapsilosis & - & Guo et al. (2014) \\
\hline CPAR5 & JX512916 & C. parapsilosis & - & Guo et al. (2014) \\
\hline CPAR6 & JX512917 & C. parapsilosis & - & Guo et al. (2014) \\
\hline CPAR7 & JX512918 & C. parapsilosis & - & Guo et al. (2014) \\
\hline CPAR8 & JX512919 & C.parapsilosis & - & Guo et al. (2014) \\
\hline
\end{tabular}

All reactions were carried out in $2 \mathrm{~mL}$ Tris- $\mathrm{HCl}$ buffer $\left(0.05 \mathrm{~mol} \mathrm{~L}^{-1}, \mathrm{pH} 8.0\right)$ comprising $1 \mathrm{~g} \mathrm{~L}^{-1}$ DKTP with addition of $10 \mathrm{~g} \mathrm{~L}^{-1} \mathrm{glucose}$ and $0.02 \mathrm{mmol} \mathrm{L}^{-1} \mathrm{NADP}^{+}$at $30^{\circ} \mathrm{C}$ and $200 \mathrm{rpm}$ for $12 \mathrm{~h}$. All the results were the average of three parallel replicates

$\mathrm{H}$, or $\mathrm{NAD}(\mathrm{P})^{+}$, and appropriate amount of the purified CR2-L-GDH. The reactions for activity assay were carried out at $30{ }^{\circ} \mathrm{C}$. The molar extinction coefficient of NAD(P)H was $6220 \mathrm{~L} \mathrm{~mol}^{-1} \mathrm{~cm}^{-1}$. One unit (U) of enzyme activity was defined as $1 \mu \mathrm{mol}$ of $\mathrm{NAD}(\mathrm{P}) \mathrm{H}$ consumed or generated per minute under the assay conditions. The protein concentration was determined using Bradford reagents (Bio-Rad) as a standard.

Initial velocities at various concentrations of the substrate DKTP $\left(0.05-1.0 \mathrm{mmol} \mathrm{L}^{-1}\right)$ or the co-substrate glucose $\left(0.15-1.2 \mathrm{mmol} \mathrm{L}^{-1}\right)$ were measured at $30{ }^{\circ} \mathrm{C}$ to obtain the apparent $K_{\mathrm{m}}$ values of the purified enzyme CR2-L-GDH. For activity assay to calculate kinetic parameters, the cofactor of NADPH or $\mathrm{NADP}^{+}$at saturated concentration towards the enzyme was added in the reaction mixture. The kinetic parameters were further determined from Lineweaver-Burk plots.

\section{Asymmetric reduction of DKTP and conditions optimization}

The reaction involving free CR2 and GDH was carried out in $10 \mathrm{~mL}$ TEA buffer $\left(0.1 \mathrm{~mol} \mathrm{~L}^{-1}, \mathrm{pH} 8.0\right)$ comprising $10 \mathrm{~g} \mathrm{~L}^{-1}$ DKTP, $100 \mathrm{~g} \mathrm{~L}^{-1}$ glucose, $0.02 \mathrm{mmol} \mathrm{L}^{-1}$ $\mathrm{NADP}^{+}$, appropriate amount of CR2 crude enzyme (total soluble protein $2 \mathrm{~g} \mathrm{~L}^{-1}$ ), and GDH crude enzyme with the activity equivalent to CR2. The fusion protein CR2-L-GDH-mediated reduction was carried out in $10 \mathrm{~mL}$ TEA buffer $\left(0.1 \mathrm{~mol} \mathrm{~L}^{-1}, \mathrm{pH} 8.0\right)$ comprising $20 \mathrm{~g} \mathrm{~L}^{-1}$ DKTP, $40 \mathrm{~g} \mathrm{~L}^{-1}$ glucose, $0.2 \mathrm{mmol} \mathrm{L}^{-1}$ $\mathrm{NADP}^{+}$, and appropriate amount of CR2-L-GDH crude enzyme (total soluble protein $2 \mathrm{~g} \mathrm{~L}^{-1}$ ). The above reactions were conducted at $30{ }^{\circ} \mathrm{C}$ and $200 \mathrm{rpm}$ for $12 \mathrm{~h}$. After reaction, the mixture was centrifuged at $18,000 \times g$ for $30 \mathrm{~min}$ and the supernatant was extracted with ethyl acetate by vigorous mixing. The resulted organic layer was filtered through $0.22 \mu \mathrm{m}$ PVDF syringe filter (Troody Technology, Shanghai, China) for further analysis.

The reaction conditions were optimized by analyzing the optical purity and yield of product under various parameters, including $\mathrm{pH}$ values ranging from 7.6 to 8.6 ( $0.1 \mathrm{~mol} \mathrm{~L}^{-1}$ TEA buffer), reaction temperature varying from 20 to $45^{\circ} \mathrm{C}$, and DKTP concentrations ranging from 10 to $50 \mathrm{~g} \mathrm{~L}^{-1}$.

To determine the optimal amounts of the added cofactor and co-substrate, the corresponding reaction parameters, involving $\mathrm{NADP}^{+}$concentrations ranging from 0.005 to $0.2 \mathrm{mmol} \mathrm{L}^{-1}$ and glucose concentrations ranging from 5 to $200 \mathrm{~g} \mathrm{~L}^{-1}$, were analyzed for their effects on (S)-DHTP production from asymmetric reduction of DKTP by the catalytic system involving free CR2 and $\mathrm{GDH}$ or the fusion protein CR2-L-GDH. 


\section{Analytical methods}

The optical purity and yield of (S)-DHTP were determined by normal-phase high-performance liquid chromatography (HP 1100, Agilent, USA) equipped with a Chiralcel OZ-H column $(4.6 \mathrm{~mm} \times 250 \mathrm{~mm}$; Daicel Chemical Ind., Ltd., Japan) and a ultraviolet absorption detector. The analysis was conducted with a mobile phase consisting of hexane and 2-propanol and diethyl amine $(80: 20: 0.1, \mathrm{v} / \mathrm{v} / \mathrm{v})$ at a flow rate of $1.0 \mathrm{~mL} \mathrm{~min}^{-1}$ and detected at $241 \mathrm{~nm}$. The column temperature was set at $30{ }^{\circ} \mathrm{C}$. The retention times for $(S)$-DHTP, $(R)$-DHTP, and DKTP were $6.51,8.13$, and $5.87 \mathrm{~min}$, respectively. The e.e. value of DHTP was calculated based on the peak areas of $(S)$ - and (R)-DHTP (Soni and Banerjee 2005).

\section{Results and discussion}

\section{Selection of candidate enzyme for (S)-DHTP production from DKTP reduction}

The recombinant enzymes used in this study were expressed according to the protocol involving optimized conditions as described previously (Li et al. 2016). Then the cell-free extracts of recombinant enzymes were employed for catalyzing asymmetric reduction of DKTP to produce (S)-DHTP. As shown in Table 1, only CR2 and KRD were active towards the substrate DKTP to produce the optically active DHTP in $(S)$-configuration (Fig. 2), while other enzymes showed no catalytic capability towards the substrate, indicating that most of the involved enzymes do not have obvious capabilities of acting to the substrate possessing heterocyclic group. Compared to KRD, CR2 was more efficient in the perspective of productivity (Table 1), and hence the carbonyl reductase CR2 was selected as the suitable enzyme for further biocatalysis.

For the reaction system involving the crude enzymes of CR2 and GDH, the desired product (S)-DHTP with optical purity over $99.9 \%$ e.e. and yield of $90.43 \%$ was obtained from $10 \mathrm{~g} \mathrm{~L}^{-1}$ DKTP at $30{ }^{\circ} \mathrm{C}$ and $\mathrm{pH}$ 8.0, in the presence of $120 \mathrm{~g} \mathrm{~L}^{-1}$ glucose. When the substrate concentration was increased up to $20 \mathrm{~g} \mathrm{~L}^{-1}$, however, the yield of (S)-DHTP decreased significantly to $47.25 \%$, which would be probably attributed to cofactor deficiency, besides the nature of substrate inhibition towards the functional enzyme.

\section{Fusion expression of CR2 and GDH and its catalytic behavior}

To further enhance the production of $(S)$-DHTP from DKTP reduction, GDH, as the coupled enzyme for recycling of the necessary cofactor, was supposed to be integratedly expressed with CR2 in a fusion form by introducing the peptide linker of aligned spacing sequence. The recombinant E. coli BL21(DE3)/
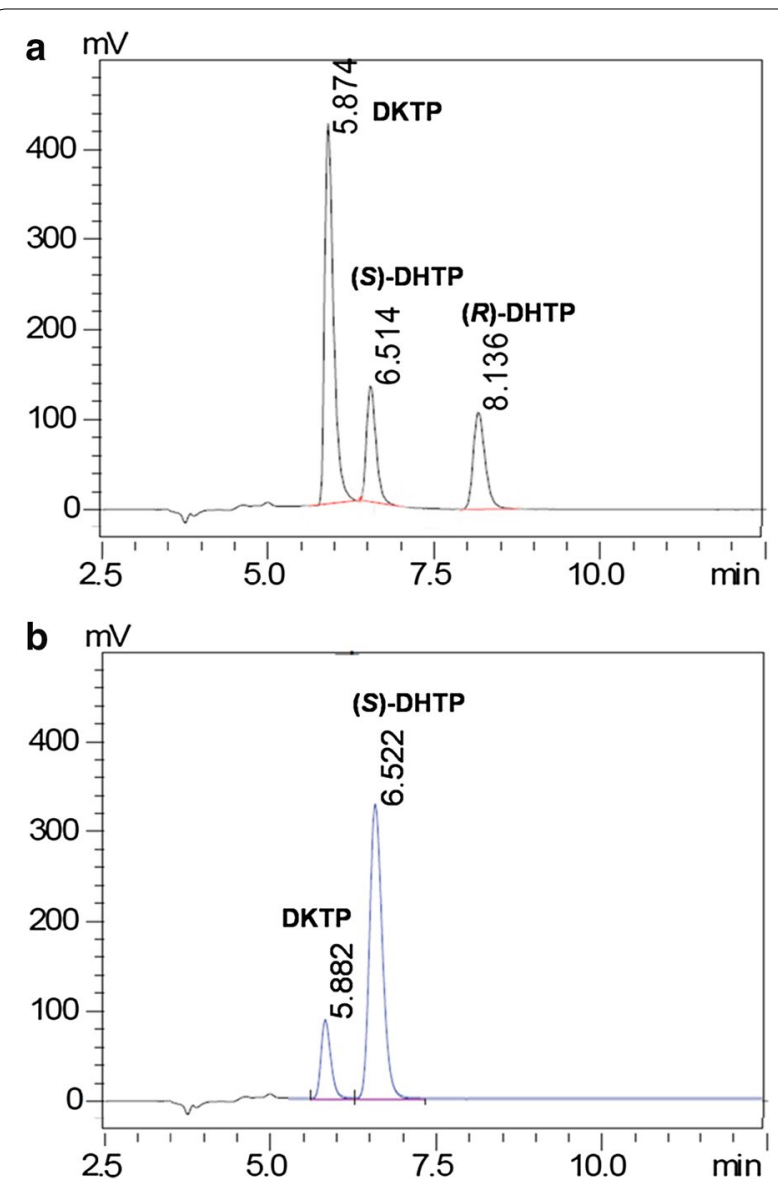

Fig. 2 Asymmetric reduction of DKTP by recombinant carbonyl reductase. a Standard samples of DKTP, (S)-DHTP and (R)-PED; b reaction products

pET-28a-cr2-l-gdh cells were induced with $1.0 \mathrm{mmol} \mathrm{L}^{-1}$ IPTG and supplied for SDS-PAGE analysis. Comparison analysis between CR2 and the fusion protein on SDSPAGE suggested that the fusion enzyme CR2-L-GDH was successfully constructed and expressed with the expected molecular weight, corresponding to the sum of both the theoretical molecular weights of CR2 $(39.8 \mathrm{kDa})$ and GDH (28.5 kDa) (Fig. 3).

As the fusion enzyme CR2-L-GDH involving both CR2 and GDH can be active towards both the substrate DKTP and the coupled co-substrate glucose, it would be necessary to evaluate the fusion enzyme by measuring its activities and kinetic parameters towards the two substrates, respectively. As shown in Table 2, the $K_{\mathrm{m}}$ values of CR2-L-GDH towards DKTP and glucose were 0.32 and $0.47 \mathrm{mmol} \mathrm{L}^{-1}$, respectively, suggesting its comparable affinities for DKTP and glucose. On the other hand, CR2L-GDH exhibited higher $k_{\text {cat }} / K_{\mathrm{m}}$ value to DKTP than to glucose, indicating the fusion enzyme was more favorable for catalyzing the bioreduction of DKTP and more 


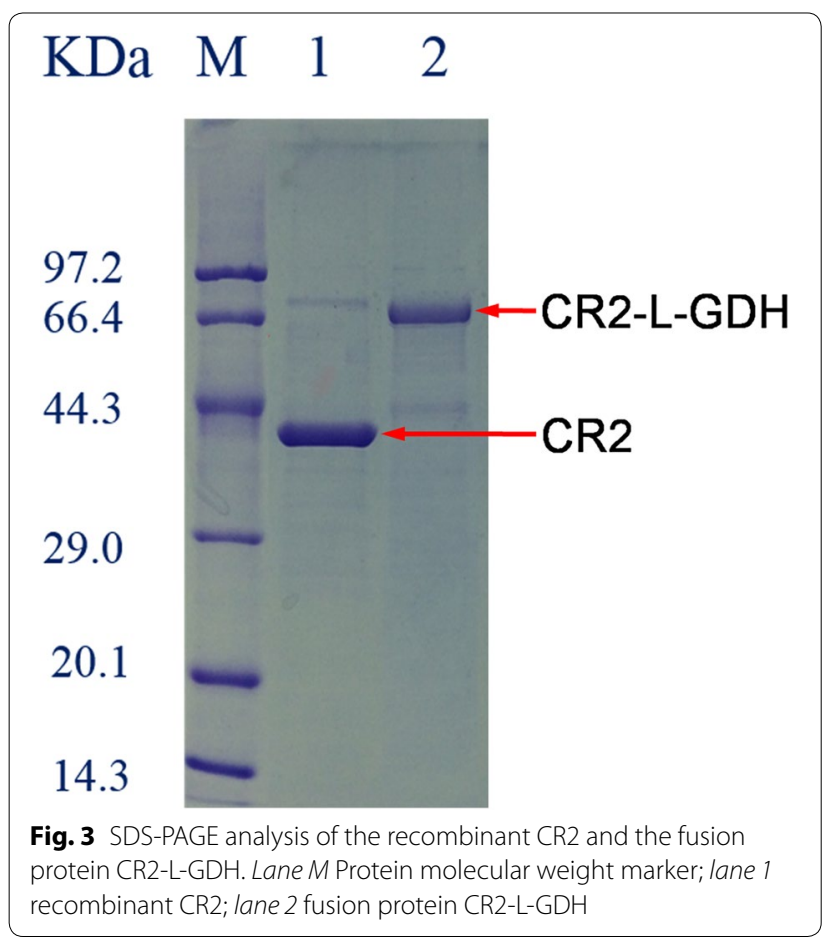

glucose should be loaded in the reaction system. Using the cell-free extract of recombinant $E$. coli BL21(DE3)/ pET-28a-cr2-l-gdh as the catalyst, with DKTP of $20 \mathrm{~g} \mathrm{~L}^{-1}$, optically pure $(S)$-DHTP ( $>99.9 \%$ e.e.) was obtained at the yield of $83.26 \%$ at $30{ }^{\circ} \mathrm{C}$ and $\mathrm{pH} 8.0$ (TEA buffer). These results indicated that it would be much potential to improve the reaction efficiency under increased substrate concentration of $20 \mathrm{~g} \mathrm{~L}^{-1}$ by the fusion enzyme CR2-L-GDH.

\section{Effects of pH and temperature on CR2-L-GDH catalyzing DKTP reduction}

It is well known that $\mathrm{pH}$ plays a crucial role in biocatalytic reactions. The ionic state of substrate and enzyme, especially the local polarity of active site in enzyme, would be generally determined by the $\mathrm{pH}$ condition of corresponding reaction. Change of $\mathrm{pH}$ value of reaction buffer could not only influence the selectivity and activity of the functional enzymes involved in the reaction, but also the efficiency of the required cofactor regeneration in whole-cell or cell-free systems, which in turn affects the synthesis of desired product in terms of optical purity and yield consequently (Silva et al. 2012). For CR2-L-GDH catalyzing DKTP reduction, the optical purity of final product kept constant with the change of initial $\mathrm{pH}$ values, while the yield of $(S)$-DHTP was increased with the alteration of $\mathrm{pH}$ from 7.6 to 8.4 (Fig. 4a), which might be due to the generation of gluconic acid from GDH-catalyzed glucose oxidation. Thus, basic condition at initial $\mathrm{pH} 8.4$ was favorable for CR2-L-GDH catalyzing DKTP reduction.

Reaction temperature would also have obvious effects on activity, selectivity, and stability of biocatalysts including whole cells and enzymes, and even reaction rate and equilibrium as well. As shown in Fig. 4b, within the tested temperature range from 20 to $45{ }^{\circ} \mathrm{C},(S)$-DHTP was prepared with high optical purity over $99.9 \%$ e.e. However, the yield of the product was improved with the increase of reaction temperature from 20 to $40{ }^{\circ} \mathrm{C}$, and higher temperature above $40^{\circ} \mathrm{C}$ led to a sharp drop in the yield, which would be attributed to partial inactivation of the enzyme at a relatively higher reaction temperature. Therefore, the reaction temperature at $40{ }^{\circ} \mathrm{C}$ was considered as the favorable factor for CR2-L-GDH catalyzing DKTP reduction.

\section{Effect of substrate concentration on CR2-L-GDH catalyzing DKTP reduction}

The amount of substrate loading is a key issue for biocatalytic application potential. However, substrate inhibition has generally become a common issue for almost all of the biocatalytic processes (Zhang et al. 2014). Thus, effect of concentration of the substrate DKTP on the fusion enzyme CR2-L-GDH catalyzing asymmetric reduction was studied here to establish an efficient biocatalytic system for the production of $(S)$-DHTP. As shown in Fig. 5, substrate concentration did not have much impact on optical purity of the product, while the yield of $(S)$-DHTP decreased obviously with the increase of substrate concentration, especially when the amount of DKTP was increased from 20 to $25 \mathrm{~g} \mathrm{~L}^{-1}$ in the reaction system. The effect of substrate inhibition might be resulted from the toxicity of the non-natural substrate towards the enzyme. To further enhance the reaction efficiency of DKTP bioreduction, the substrate concentration of $20 \mathrm{~g} \mathrm{~L}^{-1}$ was

Table 2 Kinetic parameters of the fusion enzyme CR2-L-GDH towards DKTP and glucose, respectively

\begin{tabular}{|c|c|c|c|c|}
\hline Substrate & $V_{\max }\left(\mu \mathrm{mol} \min ^{-1} \mathrm{mg}^{-1}\right)$ & $K_{\mathrm{m}}\left(\mathrm{mmol} \mathrm{L}^{-1}\right)$ & $k_{\text {cat }}\left(\mathrm{s}^{-1}\right)$ & $k_{\text {cat }} / K_{\mathrm{m}}\left(\mathrm{L} \mathrm{mol}^{-1} \mathrm{~s}^{-1}\right)$ \\
\hline DKTP & $6.75 \pm 0.15$ & $0.32 \pm 0.05$ & $4.35 \pm 0.07$ & $1.37 \times 10^{4}$ \\
\hline Glucose & $2.58 \pm 0.12$ & $0.47 \pm 0.04$ & $1.66 \pm 0.12$ & $3.54 \times 10^{3}$ \\
\hline
\end{tabular}

All reactions for the calculation of kinetic parameters were carried out in $0.1 \mathrm{~mol} \mathrm{~L}^{-1} \mathrm{TEA}$ buffer ( $\mathrm{pH} 8.0$ ) at $30^{\circ} \mathrm{C}$. For activity assay to calculate kinetic parameters, the cofactor of $\mathrm{NADPH}$ or $\mathrm{NADP}^{+}$was added in the reaction mixture at saturated concentration towards the enzyme. All the results were the average of three parallel replicates 


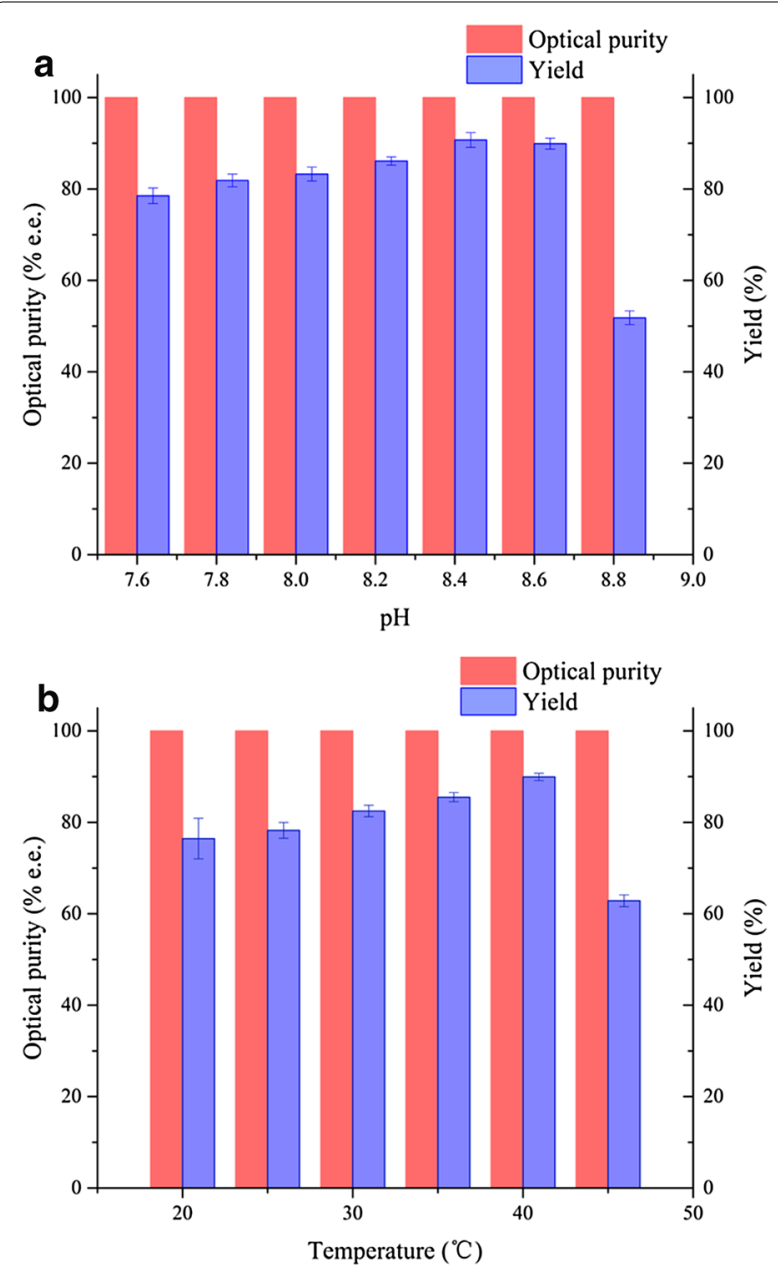

Fig. 4 Effect of pH (a) and temperature (b) on CR2-L-GDH catalyzing asymmetric synthesis of (S)-DHTP. All reactions were carried out in $10 \mathrm{~mL}$ TEA buffer $\left(0.1 \mathrm{~mol} \mathrm{~L}^{-1}\right)$ comprising $20 \mathrm{~g} \mathrm{~L}^{-1}$ DKTP with addition of $40 \mathrm{~g} \mathrm{~L}^{-1}$ glucose and $0.2 \mathrm{mmol} \mathrm{L}^{-1} \mathrm{NADP}^{+}$at $30^{\circ} \mathrm{C}$ and $200 \mathrm{rpm}$ for $12 \mathrm{~h}$. All the results were the average of three parallel replicates

adopted for the production of (S)-DHTP in term of the relatively higher space-time yield of $1.85 \mathrm{~g} \mathrm{~L}^{-1} \mathrm{~h}^{-1}$.

\section{Process regulation of CR2-L-GDH catalyzing DKTP reduction involving cofactor regeneration}

Coenzyme recycling is one of the most important issues encountered in biocatalytic reductions. Glucose as the co-substrate with equal molar ratio to the substrate DKTP would be theoretically enough to drive the biosynthesis by the fusion enzyme CR2-L-GDH. For the cellfree system involving the fusion enzyme, however, there would be a series of biochemical pathways of metabolizing glucose. Therefore, excess amount of glucose should be added into the reaction system to completely promote cofactor regeneration for CR2-L-GDH catalyzing DKTP

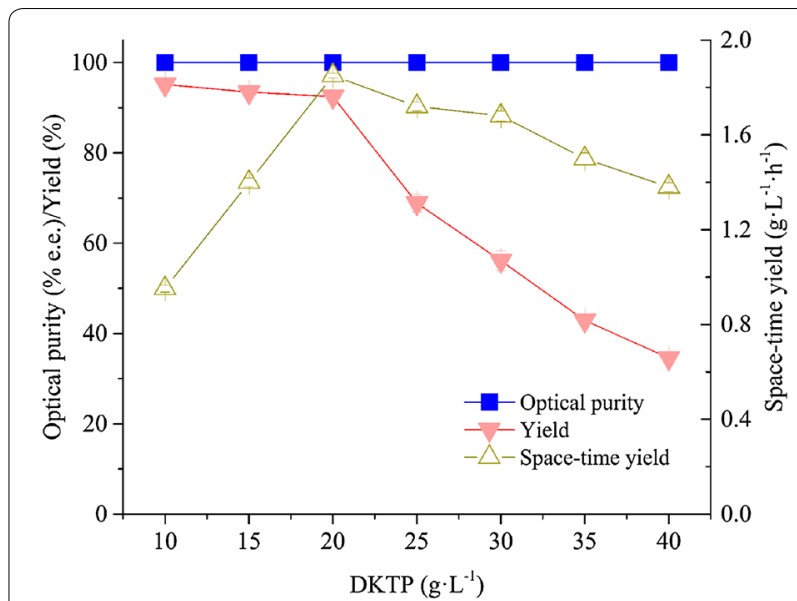

Fig. 5 Effect of DKTP concentration on CR2-L-GDH catalyzing asymmetric synthesis of (S)-DHTP. All reactions were carried out in $10 \mathrm{~mL}$ TEA buffer (0.1 mol L ${ }^{-1}, \mathrm{pH}$ 8.4) comprising 10-50 $\mathrm{g} \mathrm{L}^{-1}$ DKTP with addition of $0.2 \mathrm{mmol} \mathrm{L}^{-1} \mathrm{NADP}^{+}$at $40^{\circ} \mathrm{C}$ and $200 \mathrm{rpm}$ for $12 \mathrm{~h}$. The concentration of glucose added in the reaction was 10 folds of that of DKTP accordingly. All the results were the average of three parallel replicates

reduction. As shown in Fig. 6, by studying the effect of glucose concentration on DKTP reduction using the crude enzyme of CR2-L-GDH, addition of $40 \mathrm{~g} \mathrm{~L}^{-1}$ glucose in the reaction resulted in synthesis of (S)-DHTP ( $>99.9 \%$ e.e.) with the yield of $93.26 \%$ under $20 \mathrm{~g} \mathrm{~L}^{-1}$ DKTP after 10-h reaction.

For cofactor regeneration, total turnover number (TTN) of the cofactor is defined as the number of moles of product formed from per mole of cofactor during the

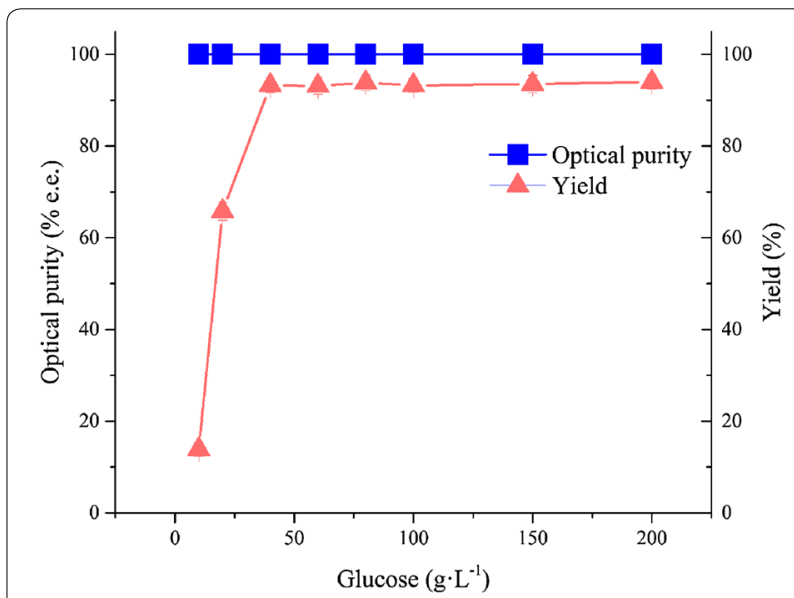

Fig. 6 Effect of glucose concentration on CR2-L-GDH catalyzing asymmetric synthesis of (S)-DHTP. All reactions were carried out in $10 \mathrm{~mL}$ TEA buffer (0.1 mol $\mathrm{L}^{-1}, \mathrm{pH}$ 8.4) comprising $20 \mathrm{~g} \mathrm{~L}^{-1}$ DKTP with addition of $0.2 \mathrm{mmol} \mathrm{L}^{-1} \mathrm{NADP}^{+}$at $40{ }^{\circ} \mathrm{C}$ and $200 \mathrm{rpm}$ for $10 \mathrm{~h}$. All the results were the average of three parallel replicates 
course of a complete reaction (Liu and Wang 2007). TTN generally indicates loss of cofactor due to degradation or incorrect regiochemistry of regeneration, and reaction rate and turnover number of biocatalyst (Zhao and van der Donk 2003). As shown in Table 3, the addition of less cofactor led to the increase of TTN. For the fixed substrate concentration of $20 \mathrm{~g} \mathrm{~L}^{-1}$, however, addition of $0.1 \mathrm{mmol} \mathrm{L}^{-1} \mathrm{NADP}^{+}$facilitated CR2-L-GDH catalyzing DKTP reduction, giving (S)-DHTP in the yield of $94.87 \%$.

After adjusting the fusion enzyme-catalyzed reaction by adding suitable amount of cofactor and glucose, during the reaction progress, optically pure $(S)$-DHTP ( $>99.9 \%$ e.e.) was produced from $20 \mathrm{~g} \mathrm{~L}^{-1}$ DKTP and accumulated at the yield reaching $97.66 \%$ under the optimal catalytic conditions after reaction for 8 h (Fig. 7), resulting in the space-time yield of $2.44 \mathrm{~g} \mathrm{~L}^{-1} \mathrm{~h}^{-1}$. In comparison with the previously reported literature $(\mathrm{Ou}$ et al. 2014), the substrate concentration was increased 5 times with 24-fold increase of space-time yield. Consequently, compared with the catalytic system involving free CR2 and GDH, the fusion enzyme CR2-L-GDH was more efficient for catalyzing asymmetric reduction of DKTP to produce optically pure (S)-DHTP, giving 2.1fold increase of the production yield towards $20 \mathrm{~g} \mathrm{~L}^{-1}$ DKTP. On the other hand, (S)-DHTP was synthesized at the yield over $90 \%$ with the substrate concentration increased from 10 to $20 \mathrm{~g} \mathrm{~L}^{-1}$ (Table 4). Since the crude enzyme (total soluble protein $2 \mathrm{~g} \mathrm{~L}^{-1}$ ) was used at the fixed enzyme loading level, it would be promising to further improve the synthesis of optically pure (S)-DHTP under higher substrate concentration by employing more fusion enzyme of CR2-L-GDH and regulating the corresponding reaction process.

\section{Conclusion}

The NADPH-dependent CR2 with excellent enantioselectivity was selected for catalyzing asymmetric reduction of DKTP to (S)-DHTP. To enhance the catalytic

Table 3 Effect of NADP ${ }^{+}$concentration on CR2-L-GDH catalyzing asymmetric synthesis of (S)-DHTP

\begin{tabular}{lllr}
\hline NADP $^{+}\left(\mathbf{m m o l ~ L}^{-\mathbf{1}}\right)$ & Optical purity (\% e.e.) & Yield (\%) & \multicolumn{1}{c}{ TTN } \\
\hline 0.2 & $>99.9$ & $92.75 \pm 0.21$ & 501 \\
0.1 & $>99.9$ & $94.87 \pm 0.15$ & 1024 \\
0.05 & $>99.9$ & $83.35 \pm 0.23$ & 1799 \\
0.02 & $>99.9$ & $72.46 \pm 0.18$ & 3911 \\
0.01 & $>99.9$ & $64.64 \pm 0.12$ & 6977 \\
0.005 & $>99.9$ & $50.45 \pm 0.28$ & 10,891 \\
\hline
\end{tabular}

All reactions were carried out in $10 \mathrm{~mL}$ TEA buffer $\left(0.1 \mathrm{~mol} \mathrm{~L}^{-1}, \mathrm{pH} 8.4\right)$ comprising $20 \mathrm{~g} \mathrm{~L}^{-1}$ DKTP with addition of $100 \mathrm{~g} \mathrm{~L}^{-1}$ glucose at $40^{\circ} \mathrm{C}$ and $200 \mathrm{rpm}$ for $10 \mathrm{~h}$. All the results were the average of three parallel replicates

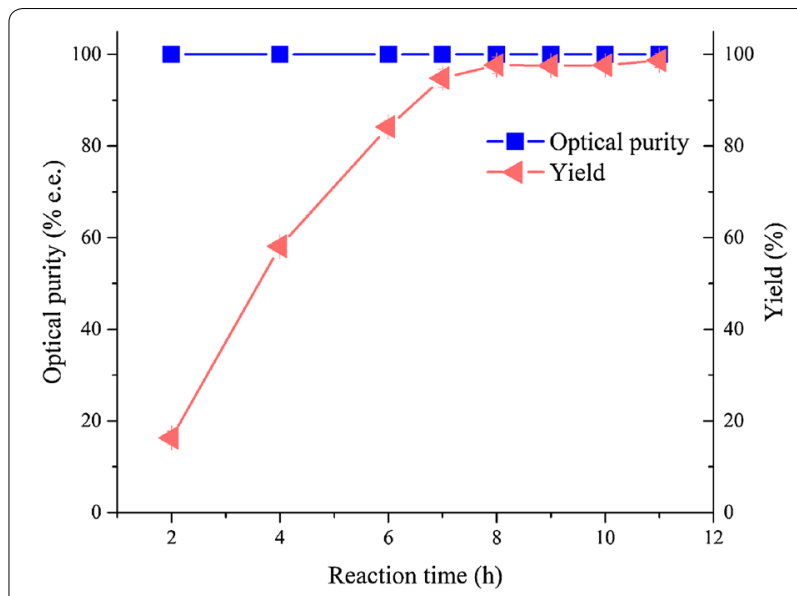

Fig. 7 Reaction process of CR2-L-GDH catalyzing asymmetric synthesis of (S)-DHTP. The reaction was carried out in $10 \mathrm{~mL}$ TEA buffer (0.1 mol L-1 pH 8.4) comprising $20 \mathrm{~g} \mathrm{~L}^{-1}$ DKTP with addition of $40 \mathrm{~g} \mathrm{~L}^{-1}$ glucose and $0.1 \mathrm{mmol} \mathrm{L}^{-1} \mathrm{NADP}^{+}$at $40^{\circ} \mathrm{C}$ and $200 \mathrm{rpm}$. All the results were the average of three parallel replicates

Table 4 Comparison of (S)-DHTP production efficiency between free CR2 and GDH and fusion enzyme CR2-L-GDH

\begin{tabular}{llll}
\hline Enzyme & $\begin{array}{l}\text { Substrate concentra- } \\
\text { tion }\left(\mathbf{g ~ L}^{-\mathbf{1}}\right)\end{array}$ & Yield (\%) & $\begin{array}{l}\text { Optical purity } \\
\text { (\% e.e.) }\end{array}$ \\
\hline CR2 and GDH & 10 & $90.43 \pm 0.37$ & $>99.9$ \\
CR2 and GDH & 20 & $47.25 \pm 0.26$ & $>99.9$ \\
CR2-L-GDH & 20 & $97.66 \pm 0.16$ & $>99.9$ \\
\hline
\end{tabular}

efficiency of CR2 catalyzing synthesis of (S)-DHTP via in situ cofactor regeneration, the chimeric gene encoding the fusion protein comprising CR2 and GDH was constructed and expressed as the fusion enzyme CR2$\mathrm{L}-\mathrm{GDH}$. By regulation of the catalytic system and reaction process, the developed CR2-L-GDH catalytic system was achieved involving $20 \mathrm{~g} \mathrm{~L}^{-1}$ DKTP, $40 \mathrm{~g} \mathrm{~L}^{-1}$ glucose, and $0.1 \mathrm{mmol} \mathrm{L}^{-1} \mathrm{NADP}^{+}$, under the optimized catalytic conditions at $40{ }^{\circ} \mathrm{C}$ and $\mathrm{pH} 8.4$ for reaction $8 \mathrm{~h}$. Consequently, optically pure (S)-DHTP (>99.9\% e.e.) with the yield of $97.66 \%$ was obtained with increased substrate concentration of $20 \mathrm{~g} \mathrm{~L}^{-1}$ DKTP using the fusion enzyme CR2-L-GDH. Therefore, the fusion strategy for construction of multi-enzyme system would be promising in potential application for efficient biosynthesis of the precursor of $(S)$-duloxetine.

\section{Authors' contributions}

$Y N, D W$, and $Y X$ designed the experiments; TS and BL performed the experiments; TS, YN, and DW wrote this manuscript. All authors read and approved the final manuscript.

\section{Author details}

${ }^{1}$ School of Biotechnology and Key Laboratory of Industrial Biotechnology, Ministry of Education, Jiangnan University, 1800 Lihu Road, Wuxi 214122, 
China. ${ }^{2}$ State Key Laboratory of Food Science and Technology, Jiangnan University, 1800 Lihu Road, Wuxi 214122, China.

\section{Acknowledgements}

$$
\text { Not applicable. }
$$

\section{Competing interests}

The authors declare that they have no competing interests.

\section{Availability of data and materials}

All data generated or analyzed during this study are included in this article.

\section{Consent for publication}

All authors have read and approved to submit it to Bioresources and Bioprocessing. There is no conflict of interest of any author in relation to the submission.

\section{Funding}

Financial supports from the National High Technology Research and Development Program of China (863 Program) (2015AA021004), the National Natural Science Foundation of China (NSFC) $(21376107,21336009,21676120)$, the Natural Science Foundation of Jiangsu Province (BK20151124), the 111 Project (111-2-06), the High-end Foreign Experts Recruitment Program (GDT20153200044), the Program for Advanced Talents within Six Industries of Jiangsu Province (2015-NY-007), the National Program for Support of Topnotch Young Professionals, the Fundamental Research Funds for the Central Universities (JUSRP51504), the Project Funded by the Priority Academic Program Development of Jiangsu Higher Education Institutions, and the Jiangsu province "Collaborative Innovation Center for Advanced Industrial Fermentation" industry development program are greatly appreciated.

\section{Publisher's Note}

Springer Nature remains neutral with regard to jurisdictional claims in published maps and institutional affiliations.

Received: 1 April 2017 Accepted: 23 April 2017

Published online: 02 May 2017

\section{References}

Bymaster FP, Dreshfield-Ahmad L, Threlkeld PG, Shaw JL, Thompson L, Nelson DL, Hemrick-Luecke SK, Wong DT (2001) Comparative affinity of duloxetine and venlafaxine for serotonin and norepinephrine transporters in vitro and in vivo, human serotonin receptor subtypes, and other neuronal receptors. Neuropsychopharmacology 25:871-880

Calam E, Gonzalez-Roca E, Fernandez MR, Dequin S, Pares X, Virgili A, Biosca JA (2016) Enantioselective synthesis of vicinal ( $R, R)$-diols by Saccharomyces cerevisiae butanediol dehydrogenase. Appl Environ Microbiol 82:1706-1721

Castellana M, Wilson MZ, Xu Y, Joshi P, Cristea IM, Rabinowitz JD, Gitai Z, Wingreen NS (2014) Enzyme clustering accelerates processing of intermediates through metabolic channeling. Nat Biotechnol 32:1011-1018

Conrado RJ, Varner JD, DeLisa MP (2008) Engineering the spatial organization of metabolic enzymes: mimicking nature's synergy. Curr Opin Biotechnol 19:492-499

Costello CA, Payson RA, Menke MA, Larson JL, Brown KA, Tanner JE, Kaiser RE, Hershberger CL, Zmijewski MJ (2000) Purification, characterization, CDNA cloning and expression of a novel ketoreductase from Zygosaccharomyces rouxii. Eur J Biochem 267:5493-5501

Dueber JE, Wu GC, Malmirchegini GR, Moon TS, Petzold CJ, Ullal AV, Prather KLJ, Keasling JD (2009) Synthetic protein scaffolds provide modular control over metabolic flux. Nat Biotechnol 27:753-759

Farrow SC, Hagel JM, Beaudoin GA, Burns DC, Facchini PJ (2015) Stereochemical inversion of (S)-reticuline by a cytochrome P450 fusion in opium poppy. Nat Chem Biol 11:728-732

Gao C, Zhang L, Xie Y, Hu C, Zhang Y, Li L, Wang Y, Ma C, Xu P (2013) Production of (3S)-acetoin from diacetyl by using stereoselective NADPH-dependent carbonyl reductase and glucose dehydrogenase. Bioresour Technol 137:111-115

Guo R, Nie Y, Mu XQ, Xu Y, Xiao R (2014) Genomic mining-based identification of novel stereospecific aldo-keto reductases toolbox from Candida parapsilosis for highly enantioselective reduction of carbonyl compounds. J Mol Catal B Enzym 105:66-73

Hall M, Bommarius AS (2011) Enantioenriched compounds via enzyme-catalyzed redox reactions. Chem Rev 111:4088-4110

Huisman GW, Collier SJ (2013) On the development of new biocatalytic processes for practical pharmaceutical synthesis. Curr Opin Chem Biol 17:284-292

Kataoka M, Kotaka A, Hasegawa A, Wada M, Yoshizumi A, Nakamori S, Shimizu $S$ (2002) Old yellow enzyme from Candida macedoniensis catalyzes the stereospecific reduction of the $\mathrm{C}=\mathrm{C}$ bond of ketoisophorone. Biosci Biotechnol Biochem 66:2651-2657

Kataoka M, Delacruz-Hidalgo A-R, Akond M, Sakuradani E, Kita K, Shimizu S (2004) Gene cloning and overexpression of two conjugated polyketone reductases, novel aldo-keto reductase family enzymes, of Candida parapsilosis. Appl Microbiol Biotechnol 64:359-366

Kataoka M, Hoshino-Hasegawa A, Thiwthong R, Higuchi N, Ishige T, Shimizu $S$ (2006) Gene cloning of an NADPH-dependent menadione reductase from Candida macedoniensis, and its application to chiral alcohol production. Enzyme Microb Technol 38:944-951

Kizaki N, Yasohara Y, Hasegawa J, Wada M, Kataoka M, Shimizu S (2001) Synthesis of optically pure ethyl (S)-4-chloro-3-hydroxybutanoate by Escherichia coli transformant cells coexpressing the carbonyl reductase and glucose dehydrogenase genes. Appl Microbiol Biotechnol 55:590-595

Lalonde J (2016) Highly engineered biocatalysts for efficient small molecule pharmaceutical synthesis. Curr Opin Biotechnol 42:152-158

Li B, Nie Y, Mu XQ, Xu Y (2016) De novo construction of multi-enzyme system for one-pot deracemization of $(R, S)$-1-phenyl-1,2-ethanediol by stereoinversion of $(S)$-enantiomer to the corresponding counterpart. J Mol Catal B Enzym 129:21-28

Liu W, Wang P (2007) Cofactor regeneration for sustainable enzymatic biosynthesis. Biotechnol Adv 25:369-384

Munoz Solano D, Hoyos P, Hernaiz MJ, Alcantara AR, Sanchez-Montero JM (2012) Industrial biotransformations in the synthesis of building blocks leading to enantiopure drugs. Bioresour Technol 115:196-207

Nakamura K, Yamanaka R, Matsuda T, Harada T (2003) Recent developments in asymmetric reduction of ketones with biocatalysts. Tetrahedron Asymmetry 14:2659-2681

Nealon CM, Musa MM, Patel JM, Phillips RS (2015) Controlling substrate specificity and stereospecificity of alcohol dehydrogenases. ACS Catal 5:2100-2114

$\mathrm{Ni}$ Y, Xu JH (2012) Biocatalytic ketone reduction: a green and efficient access to enantiopure alcohols. Biotechnol Adv 30:1279-1288

Nie Y, Xu Y, Wang H, Xu N, Xiao R, Sun Z (2008) Complementary selectivity to (S)-1-phenyl-1,2-ethanediol-forming Candida parapsilosis by expressing its carbonyl reductase in Escherichia coli for $(R)$-specific reduction of 2-hydroxyacetophenone. Biocatal Biotransform 26:210-219

Nie Y, Xiao R, Xu Y, Montelione GT (2011) Novel anti-Prelog stereospecific carbonyl reductases from Candida parapsilosis for asymmetric reduction of prochiral ketones. Org Biomol Chem 9:4070-4078

Noey EL, Tibrewal N, Jiménez-Osés G, Osuna S, Park J, Bond CM, Cascio D, Liang J, Zhang X, Huisman GW, Tang Y, Houk KN (2015) Origins of stereoselectivity in evolved ketoreductases. Proc Natl Acad Sci USA 112:E7065-E7072

Ou ZM, Zhao HB, Tang L, Zhang W, Yang GS (2014) Asymmetric synthesis of duloxetine intermediate (S)-(-)-3-N-methylamino-1-(2-thienyl)-1-propanol using immobilized Saccharomyces cerevisiae in liquid-core sodium alginate/chitosan/sodium alginate microcapsules. Bioprocess Biosyst Eng $37: 2243-2250$

Patel RN (2003) Microbial/enzymatic synthesis of chiral pharmaceutical intermediates. Curr Opin Drug Discov Devel 6:902-920

Patel RN (2008) Synthesis of chiral pharmaceutical intermediates by biocatalysis. Coord Chem Rev 252:659-701

Pazmino DET, Snajdrova R, Baas BJ, Ghobrial M, Mihovilovic MD, Fraaije MW (2008) Self-sufficient Baeyer-Villiger monooxygenases: effective coenzyme regeneration for biooxygenation by fusion engineering. Angew Chem Int Ed 47:2275-2278 
Pesti J, DiCosimo R (2003) Recent progress in enzymatic resolution and desymmetrization of pharmaceuticals and their intermediates. Curr Opin Drug Discov Dev 6:884-901

Pollard DJ, Woodley JM (2007) Biocatalysis for pharmaceutical intermediates: the future is now. Trends Biotechnol 25:66-73

Prachayasittikul V, Ljung S, Isarankura-Na-Ayudhya C, Bulow L (2006) NAD(H) recycling activity of an engineered bifunctional enzyme galactose dehydrogenase/lactate dehydrogenase. Int J Biol Sci 2:10-16

Ren Z-Q, Liu Y, Pei X-Q, Wang H-B, Wu Z-L (2015) Bioreductive production of enantiopure (S)-duloxetine intermediates catalyzed with ketoreductase ChKRED15. J Mol Catal B Enzym 113:76-81

Silva VD, Stambuk BU, da Graça Nascimento M (2012) Asymmetric reduction of (4R)-(-)-carvone catalyzed by baker's yeast in aqueous mono-and biphasic systems. J Mol Catal B Enzym 77:98-104

Soni P, Banerjee U (2005) Biotransformations for the production of the chiral drug (S)-duloxetine catalyzed by a novel isolate of Candida tropicalis. Appl Microbiol Biotechnol 67:771-777

Suehrer I, Haslbeck M, Castiglione K (2014) Asymmetric synthesis of a fluoxetine precursor with an artificial fusion protein of a ketoreductase and a formate dehydrogenase. Process Biochem 49:1527-1532

Sun Z, Lonsdale R, Ilie A, Li G, Zhou J, Reetz MT (2016) Catalytic asymmetric reduction of difficult-to-reduce ketones: triple-code saturation mutagenesis of an alcohol dehydrogenase. ACS Catal 6:1598-1605

Tang C-G, Lin H, Zhang C, Liu Z-Q, Yang T, Wu Z-L (2011) Highly enantioselective bioreduction of $\mathrm{N}$-methyl-3-oxo-3-(thiophen-2-yl) propanamide for the production of (S)-duloxetine. Biotechnol Lett 33:1435-1440

Wada M, Yoshizumi A, Furukawa Y, Kawabata H, Ueda M, Takagi H, Nakamori $\mathrm{S}$ (2004) Cloning and overexpression of the Exiguobacterium sp F42 gene encoding a new short chain dehydrogenase, which catalyzes the stereoselective reduction of ethyl 3-oxo-3-(2-thienyl) propanoate to ethyl (S)-3-hydroxy-3-(2-thienyl) propanoate. Biosci Biotechnol Biochem 68:1481-1488
Wang LJ, Li CX, Ni Y, Zhang J, Liu X, Xu JH (2011) Highly efficient synthesis of chiral alcohols with a novel NADH-dependent reductase from Streptomyces coelicolor. Bioresour Technol 102:7023-7028

Weckbecker A, Hummel W (2006) Cloning, expression, and characterization of an (R)-specific alcohol dehydrogenase from Lactobacillus kefir. Biocatal Biotransform 24:380-389

Wohlgemuth R (2010) Asymmetric biocatalysis with microbial enzymes and cells. Curr Org Microbiol 13:283-292

Yamamoto H, Mitsuhashi K, Kimoto N, Matsuyama A, Esaki N, Kobayashi Y (2004) A novel NADH-dependent carbonyl reductase from Kluyveromyces aestuarii and comparison of NADH-regeneration system for the synthesis of ethyl (S)-4-chloro-3-hydroxybutanoate. Biosci Biotechnol Biochem 68:638-649

Ye Q, Cao H, Yan M, Cao F, Zhang Y, Li X, Xu L, Chen Y, Xiong J, Ouyang P, Ying H (2010) Construction and co-expression of a polycistronic plasmid encoding carbonyl reductase and glucose dehydrogenase for production of ethyl (S)-4-chloro-3-hydroxybutanoate. Bioresour Technol 101:6761-6767

Zhang J, Tao S, Zhang B, Wu X, Chen Y (2014) Microparticle-based strategy for controlled release of substrate for the biocatalytic preparation of L-homophenylalanine. ACS Catal 4:1584-1587

Zhang D, Chen X, Chi J, Feng J, Wu Q, Zhu D (2015) Semi-rational engineering a carbonyl reductase for the enantioselective reduction of $\beta$-amino ketones. ACS Catal 5:2452-2457

Zhao H, van der Donk WA (2003) Regeneration of cofactors for use in biocatalysis. Curr Opin Biotechnol 14:583-589

\section{Submit your manuscript to a SpringerOpen ${ }^{\odot}$ journal and benefit from:}

- Convenient online submission

- Rigorous peer review

- Immediate publication on acceptance

- Open access: articles freely available online

- High visibility within the field

- Retaining the copyright to your article 